\title{
50. Two Siblings with the XY-Female having Heavy Mental Retardation from the Parent with the Normal Phenotype
}

\author{
By Tetsuji Kadotani,*) Yoko Watanabe,*) and Ichiro Takemura**) \\ (Communicated by Sajiro Makino, M. J. A., June 10, 1986)
}

The repeated occurrence of the XY-female in the same couple with the normal karyotype has been a rare event and a still discussible problem for the causes. We wish to describe in this paper an additional family in which two children with the XY-female were delivered by the same couple with the normal phenotype.

Family data. The patients were two siblings and both of them had the heavy mental retardation.

Case 1. The elder sister was a 33 -year-old woman, $22.5 \mathrm{~kg}$ in weight. She was born to a 26 -year-old father and a 24-year-old mother as the first child. She was $2700 \mathrm{~g}$ at birth on 10 months of the gestation, with asphyxia. Her remarkable clinical signs were protruding tongue, flat breast, incomplete development of external genitalia, hermaphroditism, crytorchism, talipes equinovarus of both sides, muscular atrophy, hypotonia, hyperreflexia of tendo, disturbance of gaits, speech disorders, and idiot.

Case 2. The younger sister was a 29 -year-old woman, $19.0 \mathrm{~kg}$ in weight. She was born to a 30 -year-old father and a 28 -year-old mother as the second child. She was $2500 \mathrm{~g}$ at birth on 10 months of the gestation, with asphyxia. Her remarkable clinical signs were flat breast, kyphosis, the incomplete development of the external genitalia, hermaphroditism, crytorchism, club hand, calcaneus of both sides, hypotonia, muscular atrophy, disturbance of gaits, speech disorders, and idiot.

Their parents were second cousins. There was no history of abortion, still birth, and the exposure to the atomic bomb. The clinical examinations revealed that their parents were phenotypically normal showing no evidence for the mental deficiency.

Cytological findings. Chromosome preparations were made on the leucocyte cultures from the patients and their mother. Their father was dead a few years ago. The G- and Q-banding differential stainings were applied for the chromosome identification. Chromosome counts were made with 30 well-delineated metaphases in each. Two siblings' karyotypes were analysed in 8 cells by the conventional Giemsa staining, 10 cells by G-banding, and 12 cells by Q-banding differential stainings in each.

The chromosome constitution of both patients based on the conventional Giemsa specimen showed 46 chromosomes which included a single $\mathrm{Y}$ chromosome. By the G- and Q-banding analyses, it had been also revealed that the single complete Y chromosome was recognized. Then, the chromosome formula of these

*) The Kadotani Medical Research Foundation. Saijohigashi, Higashihiroshima, Hiroshima.

**) Kojika-gakuen. Awayacho, Miyoshi, Hiroshima. 
patients was given as $46, \mathrm{XY}$. Their mother was chromosomally normal with no evidence for the aberration.

Remarks and conclusion. In 1959, Jacobs et al. and Harnden and Stewart were the first to report on the XY karyotype in a patient with the pure gonadal dysgenesis. Since then, the XY-female has come to be the frequent cases in sex chromosome abnormalities. But the repeated occurrence of the XY-female

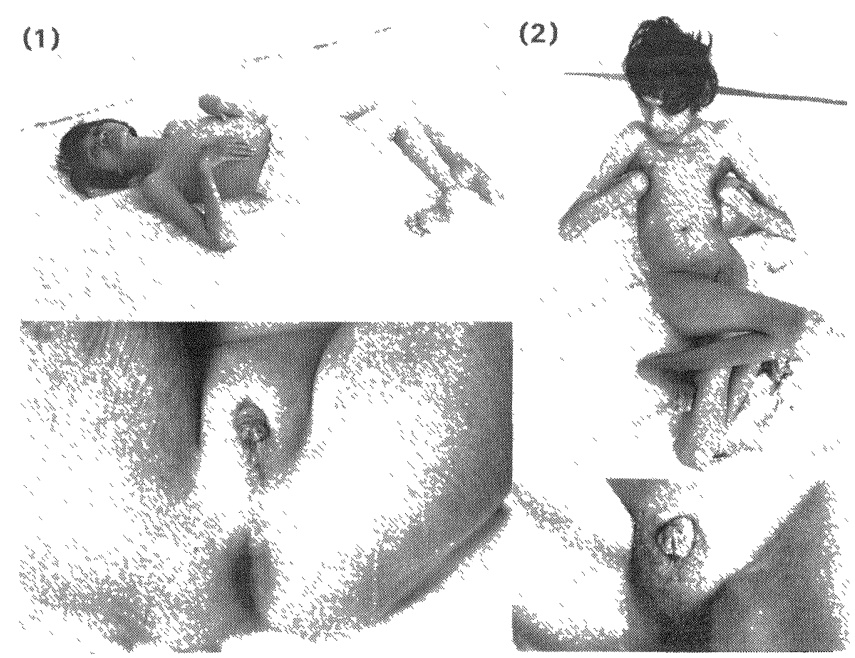

Fig. 1. External features of elder sister (1) and younger sister (2).

(1)
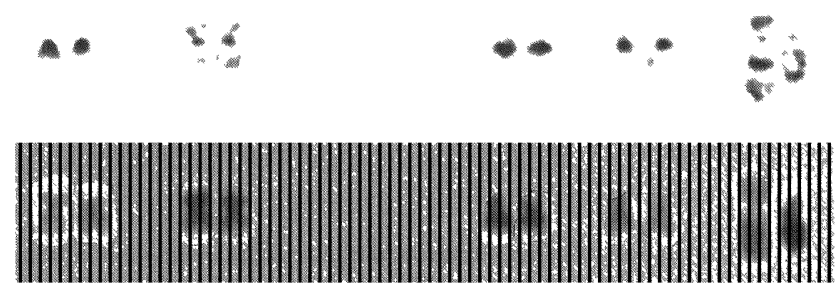

$X Y$

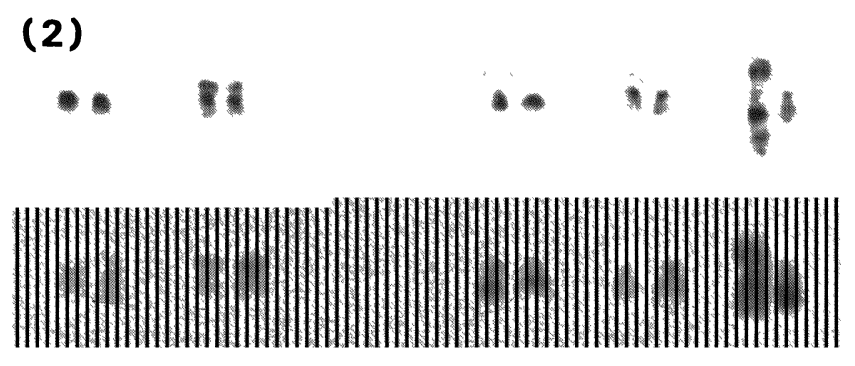

$X Y$

Fig. 2. G- and Q-banding partial karyotypes of the patients; (1) elder sister, (2) younger sister. 
in the same couple is a rare event. Cohen and Shaw (1965), and Brøgger and Strand (1965) reported on two cases of the XY-female in siblings. Espiner et al. (1970) reported on three siblings with the XY gonadal dysgenesis. Phansey et al. (1980) reported on three tall, phenotypic female siblings with the XY gonadal dysgenesis. In both of two patients of our case, were recognized not only abnormalities of the external genitalia but also the multiple malformation and heavy mental retardation.

Acknowledgements. We are cordially obliged to Emeritus Professor Sajiro Makino, M. J. A., the senior director of the Kadotani Medical Research Foundation, for improvement of this manuscript. Financial aid from the Japan Academy is gratefully acknowledged here.

\section{References}

Brøgger, A., and Strand, A. (1965) : Acta Endocrinol., 48, 490-505.

Cohen, M. M., and Shaw, M. W. (1965) : New Engl. J. Med., 272, 1083-1088.

Espiner, E. A. et al. (1970) : ibid., 283, 6-11.

Harden, D. G., and Stewart, J. S. S. (1959) : Brit. Med. J., 2, 1285-1287.

Jacobs, P. A. et al. (1959): Lancet, 2, 591.

Phansey, S. A. et al. (1980): Am. J. Obstet. Gynecol., 138, 133-138. 